\title{
Flexibility Analysis in Business Process Reengineering with Theory of Constraint using Intelligent Dynamic Workflow System
}

\author{
Shweta Tayade \\ Asst. Professor \\ Department of MCA \\ G.H. Raisoni College of Engineering, Nagpur
}

\author{
Vinay Chavan, Ph.D \\ Professor \& Head \\ Computer Science \& IT \\ S.K. Porwal College, Kamptee
}

\begin{abstract}
IT enabled organizations strive for overall improvement in performance with the use of tools capable of forecasting the stability and growth as well as failure. This paper contributes by introducing a technique and a model in Business process reengineering with Theory of constraints using dynamic workflow system enhanced with artificial intelligent 'agents' to observe the impact of flexibility on the performance of the organization. The paper also presents a model that has been verified by a developed tool which majorly deals with runtime change management capable of dealing with flexibility by change in workflow system in the domain of Human resource management.
\end{abstract}

\section{General Terms}

Workflow management system, intelligent systems, redesign, change management

\section{Keywords}

Workflow, Business Process Engineering, Flexibility, change management, Intelligent agent

\section{INTRODUCTION}

There has been tremendous increase of use of Workflow management as a suitable tool aiming at the automation of business processes to improve the speed and efficiency of an organization in business process reengineering approach. As the complexity, uncertainty and risk in business operations have increased, there is an increased demand on flexible and dynamic workflow management Workflow evolution at runtime after change realization, an important aspect in workflow management systems, has gained growing attention in business process management.

However, evolution techniques provided in traditional workflow systems lack choices and flexibility to handle dynamic change, managing execution and modeling of flexibility and measuring performance in BPR.

The proposed study is based upon an organizational business process redesign. The major problem of the organization undergoing redesign was 'throughput'. After an extensive study over literature business process reengineering with Theory of constraint (TOC) approach was found to be suitable. By using the TOC's - Thinking process, the constraint or the core problem was identified to be 'rigidity'. This constraint's effect was over all dimensions of organization. The method of identification of the constraint is not the topic of discussion of this paper due to time $\&$ space limitation.

As workflow is proved to be most useful tool for implementation, the proposed study revolves around the constraint of the organization 'rigidity', hence, is exploited by designing a workflow model and implementing it by a proposed tool. The final outcome is a high performance of the organization with a dynamic workflow management system.

In the following section, light is thrown on literature related to BPR and workflow. The next section discusses the tool of the proposed study i.e. workflow, followed by the design and implementation of the model.

The model is implemented over and organization and results and findings are presented with contribution of the research.

\section{BPR RELATED WORK}

The idea of designing businesses has been around for a long time and structured methods of doing this emerged in the 1980's [1]. Business process reengineering (BPR) is perhaps the most popular business concept since the 1990's [1]. Many organizations have initiated reengineering efforts and often use the term reengineering to describe what they do be it incremental process improvements, downsizing to even new information technology systems. This signifies the popularity of the concept of reengineering among businesses and even the public sector.

A BPR project starts when an organization is faced with the need to change its business process to make improvements in its quality, cost, service, lead-times, outcomes or flexibility. The turbulence of the organizational environment forces the manager to change the structure and the way of doing their business processes according to environmental changes and customer demands. For this reason, BPR has become one of the most impotent managerial tools in this century. BPR is the analysis and design of workflows and processes within and between organizations [1], [2].

Therefore, BPR objective stated in [1]:

- To dramatically reduce cost

- $\quad$ Speed: To reduce time [5]

- To dramatically improve output quality

- To dramatically improve Quality of work life (QWL)/ learning/ empowerment.

- Productivity: To improve drastically effectiveness and efficiency 


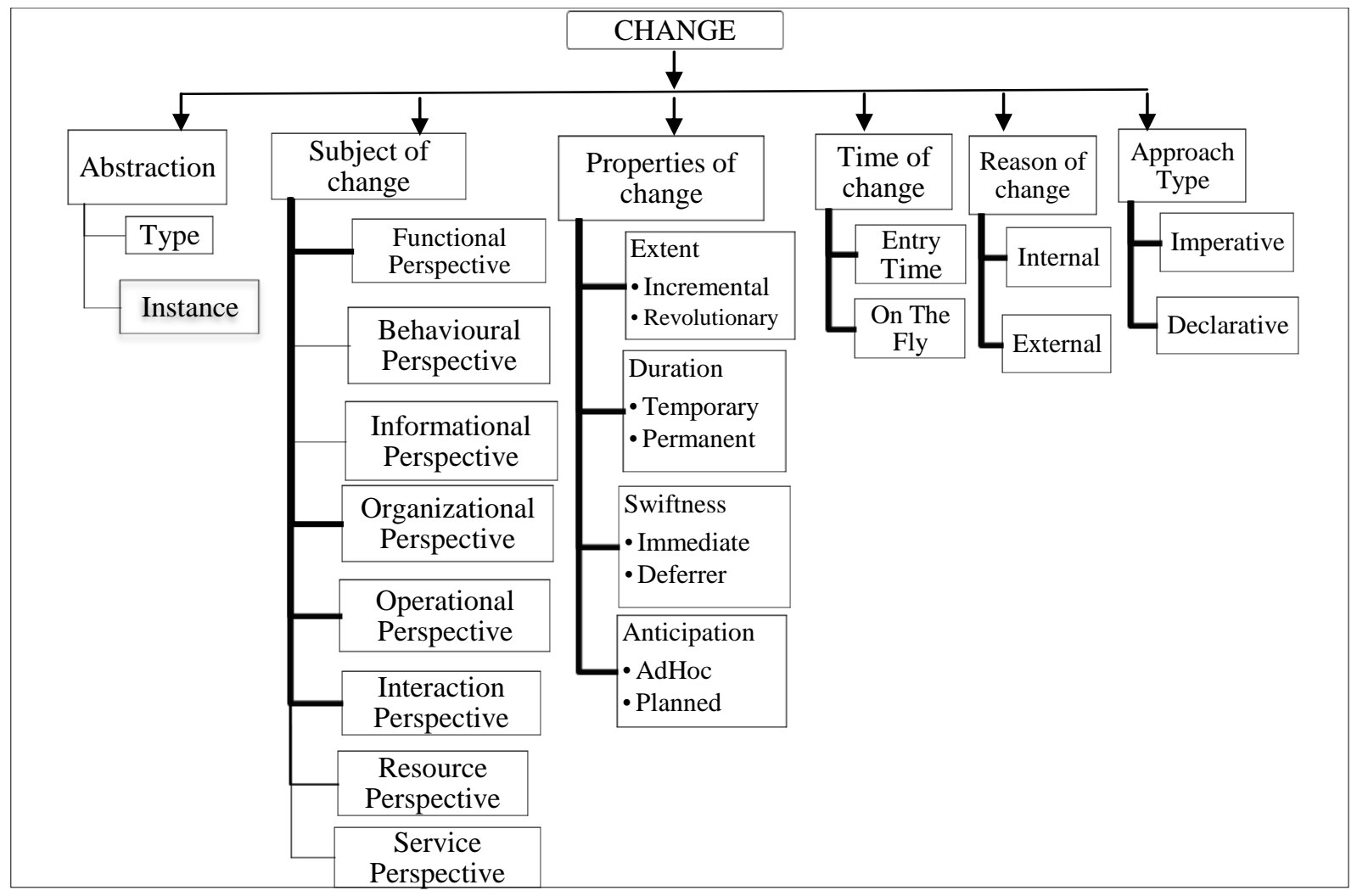

Fig. 1 Taxonomy of flexibility

- Flexibility: To develop adaptive processes and structures for changing conditions and competition. Being closer to the customer the company can develop the awareness mechanisms to rapidly spot the weak points and adapt to new requirements of the market [3],[4],[5].

- Productivity: To improve drastically effectiveness and efficiency

\section{FLEXIBILITY AND ANALYSIS}

There are different score measure on notions of flexibility in business processes. Since flexibility is that the capability of adjusting, it may be classified with relation to the categories of changes it permits. The taxonomy bestowed in Fig. 1 includes 6 orthogonal dimensions: the abstraction level of the modification, the subject of change, the properties of the change, (which embrace extent, duration, swiftness, anticipation) time of modification, reason of modification and approach type.

The need for process flexibility ensures that the "fit" between actual business processes and the technologies that support them are maintained in changing environments [18],[19]. The notion of flexibility is often viewed in terms of the ability of an organization's processes and supporting technologies to adapt to these changes [13], [8]. An alternate advanced view in [9] is that flexibility should be considered from the opposite perspective i.e. in terms of what stays the same not what changes. Indeed, a process can only be considered to be flexible if it is possible to change it without needing to replace it completely[21]. Hence, flexibility is effectively a balance between change and stability that ensures that the identity of the process is retained [22], [23]. The flexibility discussion presently accessible in literature revolves round the issues and approaches to amendment throughout the method execution [24][25]. The Table 1.1 is bestowed which provides a flexibility analysis over some recent year of analysis.

\section{WORKFLOW WITH FLEXIBILITY - AN IMPLEMENTATION TOOL OF BPR}

Two notions square measure within the attentiveness of those developments, BPR and progress Management. This new developed interest in business processes and their design and informatization is proof that this can be on the one hand a distinct segment that has been neglected within the past, and on the opposite a vital space which may considerably improve performance and aggressiveness of a corporation to produce a specified output for a particular customer or market". Riemer (1998) describes business processes in an object-oriented style: "business processes are series of steps that change states of business objects (that is, customers, orders and inventory), thereby causing business events". However, majorly it is concerned with customer-orientation. Thus, the outputs of business processes should not only achieve the company's objectives, but also need to satisfy customers' requirements. From these definitions business processes can be said to start and end with customers and the value of business processes is dependent upon customers. 
Table 1 Categories of Flexibility \& scope

\begin{tabular}{|c|c|c|c|c|}
\hline $\begin{array}{l}\text { Sr. } \\
\text { No }\end{array}$ & Flexibility & Year & Description & Scope/limitation/Problem \\
\hline 1. & By configuration /selection [13] & 1999 & $\begin{array}{l}\text { Supports preventive treatment of } \\
\text { changes; reduces need for change }\end{array}$ & $\begin{array}{l}\text { Workflow language needs to } \\
\text { be extended by application } \\
\text { specific constructs }\end{array}$ \\
\hline 2. & $\begin{array}{l}\text { By adaptation }[13] \\
\text { (A-posteriori) }\end{array}$ & 2000 & Supports follow up treatment of changes & Requires controlling \\
\hline 3. & $\begin{array}{l}\text { By design }[14] \\
(\text { A-priori })\end{array}$ & 2007 & $\begin{array}{l}\text { Alternative execution paths at design } \\
\text { time selection of the most appropriate } \\
\text { execution path to be made at runtime }\end{array}$ & Limited to Design time only \\
\hline 4. & By underspecification [14] & 2007 & $\begin{array}{l}\text { Execute an incomplete process model at } \\
\text { run-time }\end{array}$ & $\begin{array}{l}\text { Initial Model specification is } \\
\text { must }\end{array}$ \\
\hline 5. & By deviation [14] & 2007 & $\begin{array}{l}\text { Instance to deviate at runtime other than } \\
\text { planned at design time; only order change } \\
\text { allowed }\end{array}$ & $\begin{array}{l}\text { No other option other than } \\
\text { reorder }\end{array}$ \\
\hline 6. & By change $[14]$ & 2007 & $\begin{array}{l}\text { Modify a process model at run-time such } \\
\text { that one or all of the currently executing } \\
\text { process instances are migrated to a new } \\
\text { process model }\end{array}$ & $\begin{array}{l}\text { Too many standard solution } \\
\text { available to choose for a single } \\
\text { issue }\end{array}$ \\
\hline 7. & Pre Flexibility [15] & 2006 & $\begin{array}{l}\text { Which is anticipated by the designer and } \\
\text { forms part of the process definition }\end{array}$ & $\begin{array}{l}\text { Scope to design time and } \\
\text { designer form }\end{array}$ \\
\hline 8. & Just-In Time [15] responsive & 2006 & $\begin{array}{l}\text { requires an "intelligent process manager" } \\
\text { to deal with the variation as it arises at } \\
\text { runtime }\end{array}$ & $\begin{array}{l}\text { Can't be used without } \\
\text { intelligent process manager }\end{array}$ \\
\hline 9. & Short term Flexibility [16] & 2005 & $\begin{array}{l}\text { This type involves a temporary deviation } \\
\text { from the standard way of working, }\end{array}$ & Limited to instance \\
\hline 10. & Long Term Flexibility [16] & 2005 & $\begin{array}{l}\text { This involves changes to the usual way of } \\
\text { working }\end{array}$ & $\begin{array}{l}\text { No standard approach defined } \\
\text { and explained }\end{array}$ \\
\hline 11. & Type flexibility [17] & 2007 & $\begin{array}{l}\text { It arises from the diversity of information } \\
\text { being handled }\end{array}$ & $\begin{array}{l}\text { Can be utilized if information } \\
\text { is geographical located in } \\
\text { different places }\end{array}$ \\
\hline 12. & Volume Flexibility [17] & 2007 & $\begin{array}{l}\text { It arising from the amount of information } \\
\text { types }\end{array}$ & $\begin{array}{l}\text { Depends and relates to only } \\
\text { amount of information }\end{array}$ \\
\hline 13. & Structure flexibility [17] & 2007 & $\begin{array}{l}\text { It arising from the need to operate in } \\
\text { different ways }\end{array}$ & Limited to graphs only \\
\hline 14. & Meta_model flexibility [18] & 2011 & $\begin{array}{l}\text { changes are applied to workflow } \\
\text { definitions and are propagated to } \\
\text { workflow running instances }\end{array}$ & $\begin{array}{l}\text { method needs complex } \\
\text { propagation mechanisms } \\
\text { and consistency checks }\end{array}$ \\
\hline 15. & Open_point flexibility [18] & 2011 & $\begin{array}{l}\text { special points are } \\
\text { defined in a workflow model where } \\
\text { adaptation can be made either by } \\
\text { selecting } \\
\text { one path from alternatives or creating a } \\
\text { new one }\end{array}$ & $\begin{array}{l}\text { Open points have to be } \\
\text { identified } \\
\text { in advance and included in the } \\
\text { process definition }\end{array}$ \\
\hline
\end{tabular}

There are several approaches proposed in the literature to deal with flexibility and adaptability using WFMS in BPR. The nature of the flexibility, formalism and flexibility techniques are only a subset amongst multiple criteria are studied in detail as they are in context with this thesis topic.

According to [26], WFMS may be characterized as providing support in three functional areas: Build-time functions, Runtime control functions and Run-time interactions with human users and IT application tools. The study of the literature allowed us to distinguish principally two kinds of flexibility depending on the capacity of dealing with change which might be incorporated in process definitions during build-time or run-time. The design time flexibility which is a normal notion of every available workflow model, but run-time flexibility is the complex concept to be explored at business process level.
Intelligent agent technology is one of the fastest growing areas of research and system development in IT [27]. Intelligent agents and multi-agent systems represent a new way of modeling many complex information management and decision tasks. Agents also represent a new computing environment for designing and implementing complex software systems [28].

In BPR, the process to be reengineered is that the supposed business process. Davenport describes a business method as "simply a structured, measured set of activities designed to supply a given output for a selected client or market". Riemer (1998) describes business processes in associate objectoriented style: "business processes area unit series of steps that modification states of business objects (that is, customers, orders and inventory), thereby inflicting business events". 
However, majorly it's involved with customer-orientation. Thus, the outputs of business processes mustn't solely bring home the bacon the company's objectives, however additionally got to satisfy customers' needs. From these definitions business processes may be aforesaid to begin and finish with customers and also the price of business processes depends upon customers.

There are many approaches projected within the literature to handle flexibility and adaptableness with WFMS in BPR. The nature of the flexibility, formalism and flexibility techniques unit solely a set amongst multiple criteria area unit studied thoroughly as they're in context with this thesis topic. According to [26], WFMS could also be characterized as providing support in 3 purposeful areas: Build-time functions, Run-time management functions and Run-time interactions with human users and IT application tools. The study of the literature allowed us to differentiate primarily two styles of flexibility reckoning on the capability of handling change which could be incorporated in process definitions throughout build-time or run-time. The design time flexibility that may be a traditional notion of each offered workflow model, however run-time flexibility is that the complicated construct to be explored at business process level.

Intelligent agent technology is one in all the quickest growing areas of analysis and system development in IT [28]. Intelligent agents and multi-agent systems represent a replacement manner of modeling several complicated info management and call tasks. Agents additionally represent a replacement computing atmosphere for planning and implementing complicated software system systems [28].

Even then due to the standards laid by WfMC the WFMS stay restricted to 'change' in static environment. Change management has been a problem in dynamic WFMS by BPR projects as discussed above in various approaches. Flexibility modeling of WMFS for change management needs to be adjusted at runtime. Attempts have been made for providing these but there are number of issues which still remain unhandled. The modeling approaches are mainly working using either agent approach or rule based or Object oriented (OO) or Petri Net (PN) approach. Each approach has there disadvantages due to which loop holes still remains.

Globally, architectures based on these contemporary approaches needs to be follow hybrid intelligent approach or integrated to fulfill modern BPR project requirement with the help of dynamic WFMS. This is the essential requirement for the success of the BPR oriented WFMS.

\section{PROPOSED MODEL}

The proposed model uses BPR with Theory of constraint approach. The weakest link is identified as 'Flexibility', and hence, managed using Dynamic workflow system architecture (DWSA). The objective is to explore the weakest link and make it strongest contender to improve performance of the system.

The DWSA model takes into account flexibility in Functional; behavioral; Organizational; Informational and extended operational perspectives of workflow. The model is designed to address the modeling requirements of high variance, sequential workflows.

The functional structure of the model consists of building blocks which are high-level packaged flexible task definitions, organized in a intelligent structure in order to accommodate a variety of designs and handle exceptions.
The proposed model an 'Agent enhanced Intelligent Rule based Workflow System' (AIRWS) is shown in Fig. 2 depicts two stages as:

- The workflow build/design time modeling is achieved by using

i. The XML, XOML modeling technique is used for definition of workflow and implementation.

ii. The UML sequence diagram gives an overall working of the agents shows the object oriented CPN representation.

iii. The object oriented XML based structure of the model is defined at design time.

iv. Colored Petri net (CPN) a standard modeling technique depicts the overall design of workflow for the user and structural analysis on change at runtime.

v. Rules are designed for implementation of workflow.

- The Run time implementation of AIRWS consists of various methods and procedures which are rule based to handle the process change at workflow instance and definition level. The rules are defined at design time but can be changed at runtime. The change management mechanism at global and local level goes through the following phases:

i. After the change invocation by user the process of 'Proactive and predictive monitoring and 'Intermediate In-demand Monitoring Plan' agents gets active.

ii. 'Intermediate Predictive Monitoring Process' is divided in partial $\mathrm{CM}$ change management technique and intelligent evolution technique and the output is 'New evolved model temporary version'. The information agent collects monitoring data for the decision making process.

iii. The temporary version remains in memory until the results of change is analyzed. The original version before change is invoked remains unharmed and system stability is confirmed.

iv. 'Decision Making Process' agent interacts with user using the iUser agent who has initiated the change for approval of results.

v. The DMP trigger is activated by the system when change is initaited by the user.

vi. The iUser agent interaction process at runtime negotiates the changes and approves the intermediate results presented by monitoring report. This report contains the $\mathrm{CM}$ technique and evolution analysis data which is used for result approval process by user.

The complete change management process is handled by agents at different levels at runtime. 


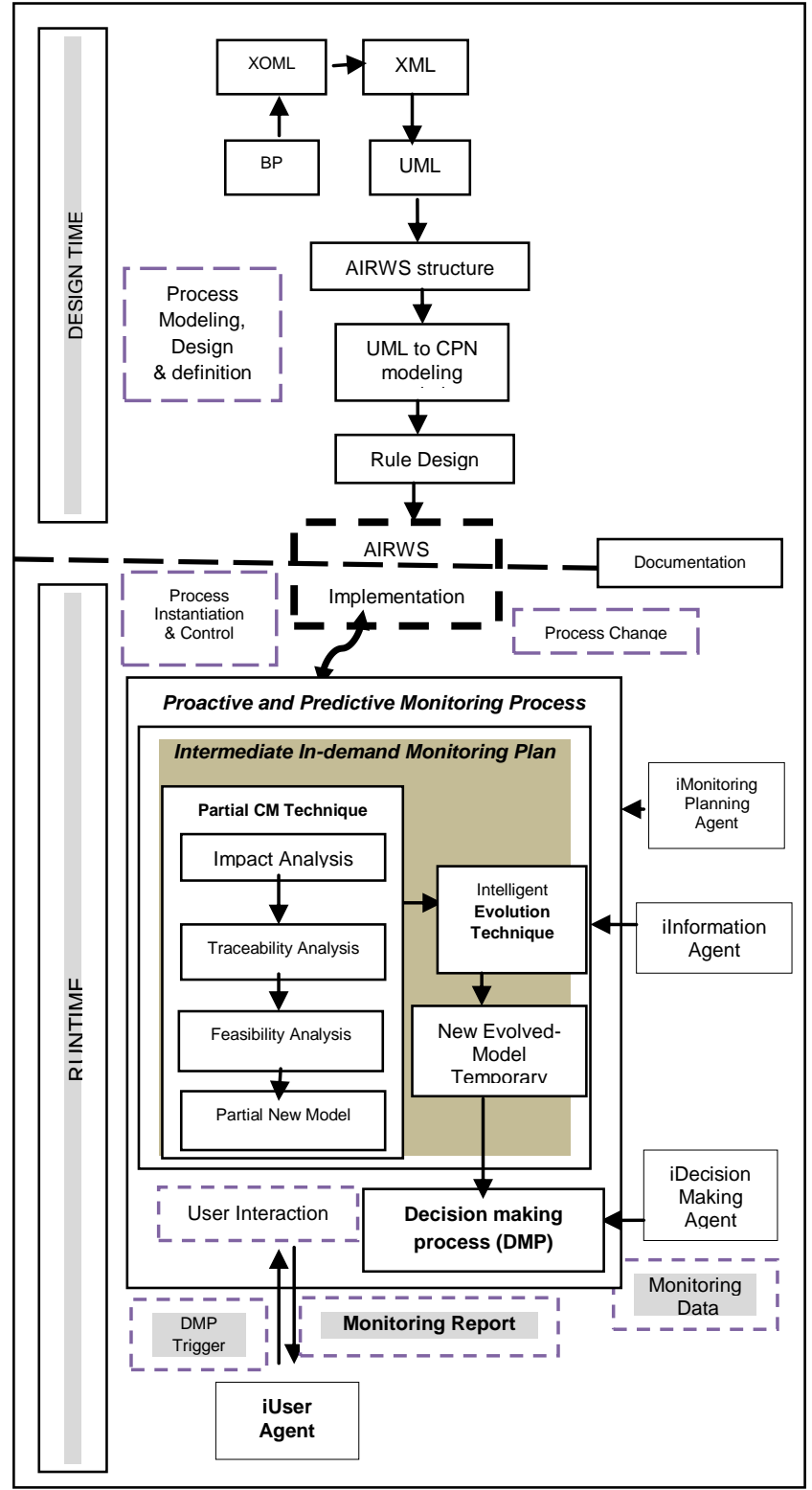

Fig 2. AIRWS Framework

\subsection{Implementation Of Airws Model}

The overall system implementation architecture component diagram of AIRWS is shown in Fig 3, tested by designed 'AutoFlow' tool which is shown in the middle of the architecture.

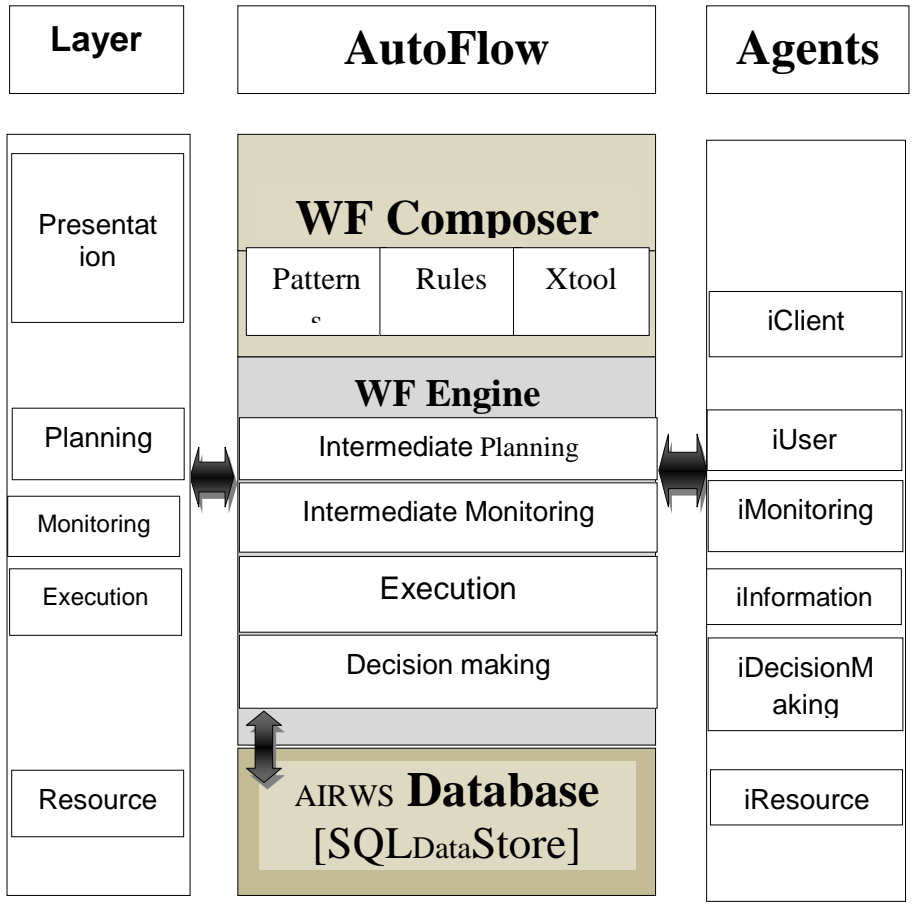

Fig 3. AutoFlow Implementation Components for AIRWS model

The Kernel of the system is the WF Engine is manager of the overall design time and runtime management. The AIRWS database consists of mechanism to maintain the following different types of data such as Process Instance Data, Workflow Relevant Data, Application Data, Control Data, Audit Data, Organization Data, Monitoring Data and Scheduling Data.

The interaction between different agent working namely iClient, iUser, iMonitoring, iResource and iDecisionMaking in three different layers of the system architecture are also seen in sequence diagram shown in Fig 3 . The agents handle the change request and carry out all the process until the decision making stage. The approved decision is then updated in the database and the model is changed.

The proposed model is implemented for 'Ticketing HelpDesk workflow system' in an organization. The proposed model was tested over a period of time in different organizations having several service departments. The ticket raised by the user towards a department is solved by the resource of the specific department. The responder is assigned either by the preference given by the user. In the absence of resource preference, the system uses intelligence and assigns the ticket according to the workload queue.

The relation object is created between the ticket and responder at runtime. If the organization cost or resource income or the profit requires improvement over time then AIRWS system offers flexibility to improve by different ways.

Flexibility at dynamic runtime on workflow instances can be used. Using High, medium and low level flexibility, system can give drastic improvement in the performance and efficiency of organization. The levels are defined by number of operations performed using flexibility. As shown in Table 1 the flexibility options are depending upon role of the user. Depending upon the number of options used by the role the level of flexibility is determined. 
The proposed model is implemented for 'Ticketing HelpDesk workflow system' in an organization. The proposed model was tested over a period of time in different organizations having several service departments. The ticket raised by the user towards a department is solved by the resource of the specific department. The responder is assigned either by the preference given by the user. In the absence of resource preference, the system uses intelligence and assigns the ticket according to the workload queue.

The relation object is created between the ticket and responder at runtime. If the organization cost or resource income or the profit requires improvement over time then AIRWS system offers flexibility to improve by different ways. Flexibility at dynamic runtime on workflow instances can be used. Using High, medium and low level flexibility, system can give drastic improvement in the performance and efficiency of organization. The levels are defined by number of operations performed using flexibility. As shown in Table 1.2 the flexibility options are depending upon role of the user. Depending upon the number of options used by the role the level of flexibility is determined.

The levels are shown in Table 1.3. The proposed model AIRWS keeps 'Flexibility' as a control to measure impact on organization cost, throughput and quality of work as based on Theory of constraints where the weakest link in organization performance is 'rigidity'. This constraint needs to be managed by rules during the execution.

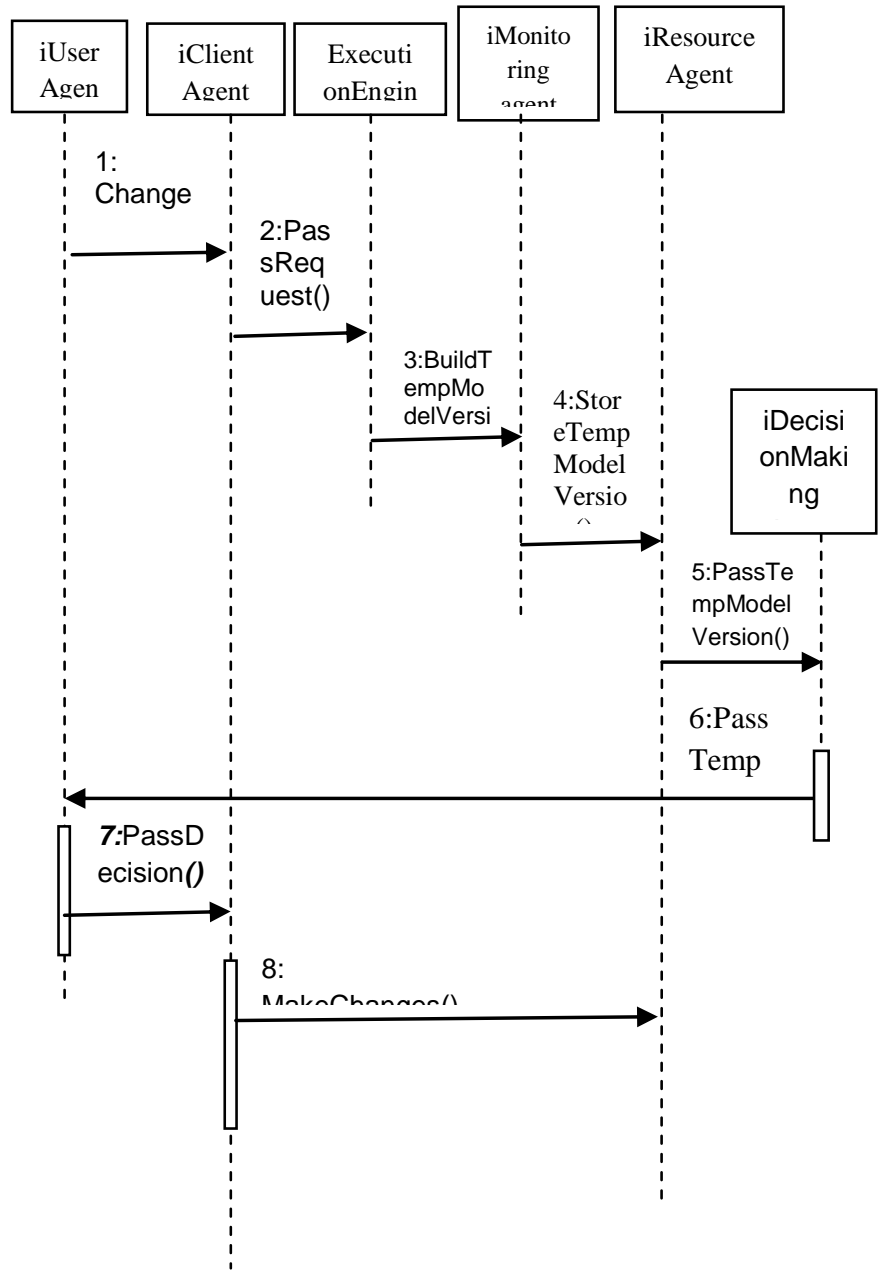

Fig 4. UML Sequence diagram for agent interaction
The rigidity constraint of a model implicitly specifies the possible execution alternatives. By the number of option used the level of flexibility applied can be fixed as shown in Table 1.2. On the basis of this level flexibility analysis is produced as a part of result.

Table 2 Flexibility options \& Role for a particular case under study

\begin{tabular}{|c|l|l|}
\hline $\begin{array}{c}\text { SR. } \\
\text { No }\end{array}$ & \multicolumn{1}{|c|}{ Flexibility options } & \multicolumn{1}{|c|}{ Role } \\
\hline 1 & Reassignment & Admin \\
\hline 2 & Schedule [Propone/Postpone] & Admin/ Resource \\
\hline 3 & Reorder & Admin/ Resource \\
\hline 4 & Requeue & Admin \\
\hline 5 & Reprioritize & Admin \\
\hline 6 & Reopen & Admin/ Resource \\
\hline
\end{tabular}

The six flexibility options Reassignment on resource perspective, schedule, reorder, requeue, reprioritize and reopen over activity or task perspective allow the role to change the workflow instance at runtime. The system automatically notifies when the cost and time factors are below or above the estimated levels. The system then automatically plans and gives the best possible option to be used for a particular case at runtime. The changes are monitored throughout and monitoring report in the form of intermediate results is put forth to the user for approval. According to the decision the results are committed to the database or rejected. Throughout, the change process working of the system is not paused any time.

Table 3 Flexibility Levels

\begin{tabular}{|l|c|c|c|}
\hline Levels & Value & $\begin{array}{l}\text { Options } \\
\text { for } \\
\text { Admin }\end{array}$ & $\begin{array}{l}\text { Options } \\
\text { for } \\
\text { Resource }\end{array}$ \\
\hline High & 1 & $=<5$ & $=3$ \\
\hline Medium & 2 & $1<5$ & $=2$ \\
\hline Low & 3 & $=1$ & $=1$ \\
\hline
\end{tabular}

\section{RESULTS}

Estimated results after implementation over a time period on rigid and flexible properties of system were:

i. improved quality of work in terms of Performance of overall system,

ii. reduced organization costs,

iii. reduced service time or speed for solving Tickets,

iv. improved productivity time,

v. increased resource income,

vi. improved customer service,

vii. improved competitiveness for rewards,

viii. introduction of appraisal of resources on basis of performance,

ix. proactive monitoring of bottlenecks in terms of errors,

x. predictive results on change invocation by customers. 
Fig 5. illustrates 'Devil's Quadrangle' to show the relation between key performance indicators (KPIs) on 4 axes such as Throughput (factor of speed), OrgCost (Organization cost), Profit and ResIncome (resource Income) using Flexibility level $=$ low, over a specific period of time and trouble tickets cases which can differ with time to time and organization to organization.

The impact on relation changes with the flexibility involved at different time.

An extensive analysis of data obtained from the organization before and after implementation of the propose model is represented by four trends of threshold values over flexibility levels. It is observed that breakthrough improvements are seen in KPIs like increased resource income, increased productive time, increased profit and reduced org cost.

Also, the deadline of all the tasks present over specific time was met with a minimum level flexibility giving an improved resource income and control on organization cost.

The appraisal of resources, which is improved to higher levels with the help of intelligent control via agents, is provided at both automatic and resource level for flexible assigning, reordering, Scheduling [Propone/Postpone], requeuing, reprioritizing and reopening of work (ticket).

By the proactive monitoring of change, the predicted results saved the productive resource time. By providing rule changing and flexible assignment at runtime, the tickets reopening were drastically lowered thereby increasing stability of system.

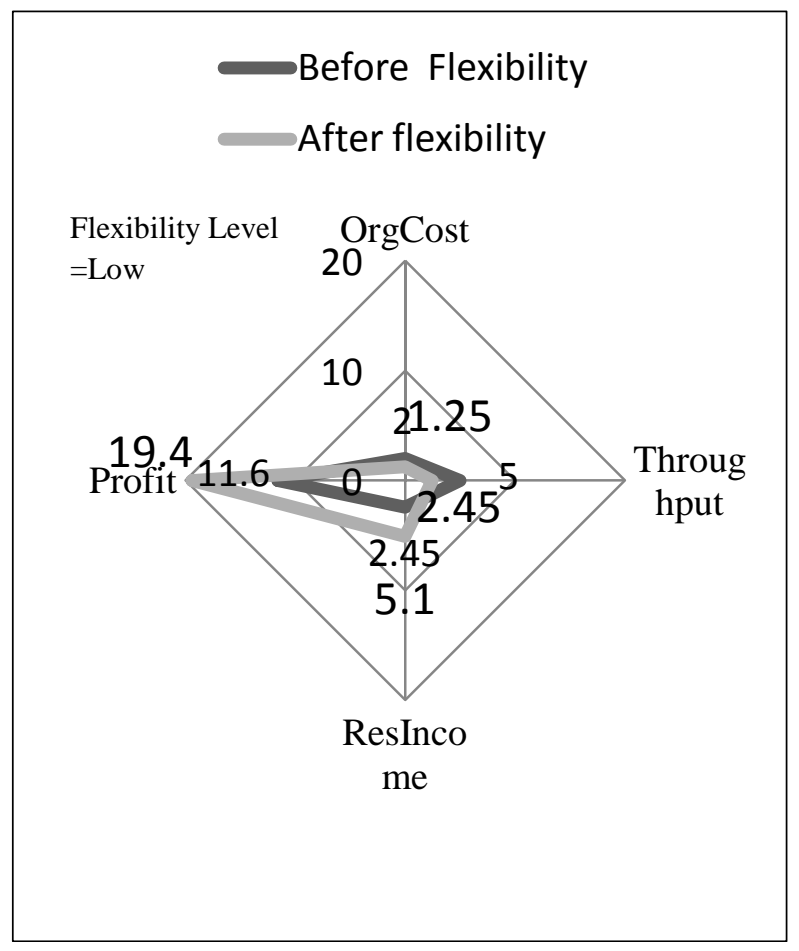

Fig 5. Devil's Quadrangle for organization before and after implementation of the propose model

The AIRWS model implemented by tool AutoFlow manages to change and predict results based on flexibility of the administrative area processes. The model was valid depending on the procedures, processes and flexibility levels.
It was confirmed that breakthrough improvements were found more frequently between the result sets before and after flexibility application in the system at runtime. Thus, instead of rigid processes, using flexibility in the same system increased the organization's benefits as well as the deadline could be achieved which increased the quality of work.

\section{CONCLUSION \& CONTRIBUTIONS}

The change management implemented by proposed model AIRWS enhances the use of flexibility in every aspect of WFMS in an organization undergoing a reengineering process. By defining the levels of flexibility used to achieve the goal of organization, the importance quantitative performance has proved the necessity of measurement of performance again in dynamic WFMS and thus cannot be ignored.

The contribution of the proposed research work is mainly in BPR and Dynamic Workflow Management areas. The flexibility characteristic of WFMS has proved to be beneficial to BPR in several ways. Some of the contributions are:

xi. The work contributes towards intelligent monitoring, dynamic modifications of workflow, management and scheduling of data intensive application workflows on distributed resources. It presents an architecture for dynamic workflow design and execution that honors the autonomy of changing workflow at runtime to achieve BPR goals that benefits the users by providing flexibility at runtime and presenting a holistic flexibility analysis.

xii. A formal BPR with TOC oriented model is presented for dynamic workflow execution, and develops methods and algorithms for implementing the functionalities of the required components in the model. It identifies a potential intelligent monitoring and analysis concern in Dynamic Workflow System Architecture, intelligent Monitoring \& Analysis, and considers the gap between expected and actual results with inbuilt monitoring functions.

xiii. The decision making process at runtime uses minimum interaction with users, but more analysis by default, thereby helping minimizing 'contact with user and dependability'.

xiv. The proposed model facilitates cooperation and teamwork communication among partners in a distributed environment using an agent-enhanced workflow management. It also helps the administrator to improve its business reengineering and enhance the performance.

\section{ACKNOWLEDGEMENTS}

This paper describes work under the Department of Inter Institutional Computer Center (I.I.C.C), Nagpur. I express gratitude towards my Supervisor Dr. Vinay Chavan, for his guidance and help throughout this project. Also, I express my humble gratitude towards Dr. Sharma, Head IICC, for his support.

\section{REFERENCES}

[1] Davenport, T.H. and J.E. Short, 1990. Summer The new industrial engineering: Information technology and business process Reengineering. Sloan Management Review, 31(4): 11-27.

[2] Farid Abdolazimian and Saeedeh Mansouri. Business Process Reengineering by Rational Unified Process 
(RUP) Methodology: In Proc World Appl. Sci. J., 4 (Supple 2): 33-42, 2008

[3] Davenport, T.H., 1993. Process innovation: Reengineering work through information technology. Boston: Harvard Business Press.

[4] Parker, J., 1993. May. An ABC guide to business process reengineering. Industrial Engineering, 25(5): 52-53.

[5] Sotiris Zigiaris: "Business Process Reengineering", Report produced for the EC funded project; January 2000

[6] Dietz, J. L. G. and Mulder H. B. F., (1996), Integrating the Strategic and Technical Approach to Business Process Reengineering, In: Business Process Modelling, Scholz-Reiter B., Stickel E.,ed., pp. 188-206

[7] Prasad B. (1999), "Hybrid re-engineering strategies for process improvement", Business Process Management Journal, Volume 5, No. 2, pp. 178 - 197

[8] Kovacic A., Krisper M., Groznik A. (2001), "Business Process Renovation: Rethinking toward e-business". Proceedings of the 7TH International Conference on ReTechnologies for Information Systems, Lyon, France, pp. 175-188, 2001

[9] Dr. Mirko Vintar, BPR and Workflow Management Paradigm in Public Administration Context: New approaches to Information Systems Analysis and Design, 2001

[10] J. Sinur, J. B. Hill: " Magic Quadrant for Business Process Management Suites", Gartner Research, PubDate 18-Oct 2010,ID Number: G00205212

[11] M. Attaran: "Exploring the Relationship between Information Technology and Business Process Reengineering. Information \& Management”, 41(5), pp. 585-596, 2004

[12] M. Netjes , I. Vanderfeesten, , and H. Reijers: "Intelligent tools for workflow process redesign: A research agenda". Vol. 3812 of Lecture Notes in Computer Science, pp. 444-453. Springer Verlag, Berlin, 2005

[13] Towards a Taxonomy of Process Flexibility (Extended Version). by: N. A. Mulyar, M. H. Schonenberg, Mans, van der Aalst 2007 ;In BPM Center Report BPM-07-11 (2007) citeulike:4814985

[14] K. Kumar and M. M. Narasipuram. Defining requirements for business process flexibility. In Workshop on Business Process Modeling, Design and Support (BP- MDS06), Proceedings of CAiSE06 Workshops, pages 137-148, 2006.

[15] P. Soffer. On the notion of flexibility in business processes. In Workshop on Business Process Modeling, Design and Support (BPMDS05), Proceedings of CAiSE05 Workshops, pages 35- 42,2005.http://mis.haifa.ac.il/ spnina/publications/flexibi lity\%20Soffer.pdf.

[16] A. Snowdon, B.C. Warboys, R.M. Greenwood, C.P. Holland, P.J. Kawalek, and D.R. Shaw. On the architecture and form of flexible process support Software Process Improvement and Practice, 12:21-34, 2007.

[17] M.H. Schonenberg, R.S. Mans, N.C. Russell, N.A Mulyar and W.M.P. van der Aals. Towards a Taxonomy of Process Flexibility (Extended Version)

[18] G. Regev and A. Wegmann. A regulation-based view on business process and supporting system flexibility. In Workshop on Business Process Modeling, Design

[19] F. Daoudi and S. Nurcan. A benchmarking framework for methods to design flexible business processes. Software Process Improvement and Practice, 12:51-63, 2007.

[20] G. Regev, I. Bider, and A. Wegmann. Defining business process flexibility with the help of invariants. Software Process Improvement and Practice, 12:65-79, 2007.

[21] G. Regev, P. Soffer, and R. Schmidt. Taxonomy of flexibility in business processes. In Proceedings of the 7th Workshop on Business Process Modelling, Development and Support(BPMDS'06), 2006 http://lamswww.epfl.ch/conference/bpmds06/taxbpflex

[22] G. Regev, I. Bider, and A. Wegmann. Defining business process flexibility with the help of invariants. Software Process Improvement and Practice, 12:65-79, 2007.

[23] G. Regev and A. Wegmann. Business process flexibility: Weick's organizational theory to the rescue. In Proceedings of the 7th Workshop on Business Process Modelling, Development and Support(BPMDS'06), 2006.

[24] Shweta Tayade, Dr. V Chavan, 2011: Challenges in Flexible Workflow Architecture: A Review. 2011 Fourth International Conference on Emerging Trends in Engineering \& Technology, 2011 - ICETET Pages: 3942, DOI: $10.1109 /$ ICETET.2011.64

[25] Shweta M. Tayade and Vinay Chavan, "Roles of Flexibility in Workflow Engineering," International Journal of Modeling and Optimization vol. 2, no. 5, pp. 644-647, 2012.

[26] WfMC-TC-1003 v1.1 (1995), V 1.1. Workflow Reference Model, January 1995.

[27] Jennings, N., Sycara, K., and Wooldridge, W. "A roadmap of agent research and development," Autonomous Agents and Multi Agent Systems, Vol 1,No 1, July 1998.

[28] Joshi, H. and Singh, M: "Multiagent Systems on the net", Communications of the ACM, Vol 42, No 3, 1999. 